This item was submitted to Loughborough's Research Repository by the author.

Items in Figshare are protected by copyright, with all rights reserved, unless otherwise indicated.

\title{
Improving the value-of-input for ideation by management intervention: an intra-organizational network study
}

PLEASE CITE THE PUBLISHED VERSION

https://doi.org/10.1016/j.jengtecman.2017.10.006

\section{PUBLISHER}

(C) Elsevier

\section{VERSION}

AM (Accepted Manuscript)

\section{PUBLISHER STATEMENT}

This work is made available according to the conditions of the Creative Commons Attribution-NonCommercialNoDerivatives 4.0 International (CC BY-NC-ND 4.0) licence. Full details of this licence are available at: https://creativecommons.org/licenses/by-nc-nd/4.0/

\section{LICENCE}

CC BY-NC-ND 4.0

\section{REPOSITORY RECORD}

Aalbers, Rick, and Wilfred Dolfsma. 2019. "Improving the Value-of-input for Ideation by Management Intervention: An Intra-organizational Network Study”. figshare. https://hdl.handle.net/2134/27330. 


\title{
IMPROVING THE VALUE-OF-INPUT FOR IDEATION BY MANAGEMENT INTERVENTION: AN INTRA-ORGANIZATIONAL NETWORK STUDY
}

\begin{abstract}
A discretionary social network in a firm is where individual employees voluntarily share new, innovative knowledge - activities in this network are essential to firm innovation. Drawing on a unique field study we quantitatively compare the situation before and after a 'simple' management intervention aimed at increasing discretionary social network activity. We submit that both the network position as well as the formal role of an individual both need to be taken into account to understand the antecedents to the voluntary exchange of valuable inputs within an organization. We find empirical evidence that someone's structural position in the network prior to intervention positively contributes to the value-of-input exchanged. Contrary to expectation, however, those employees whose task it is to professionally share valuable, new knowledge attributed the input for future innovation - ideators - fall short in leveraging a favorable position in a firm's discretionary social network.
\end{abstract}

\section{Introduction}

To successfully innovate, firms need to generate, grow and implement a sustained flow of ideas (Boeddrich 2004; Katila and Ahuja 2002) requiring an active involvement of their labor force with innovative activity (Blundell et al. 1999; Capon et al. 1990; Chaney and Devinney 1992). The research literature on organizational networks highlights how an organization’s social infrastructure can help the exchange of innovative knowledge (Cross and Cummings 2004; Cross et al. 2002; Björk and Magnusson 2009; Ahuja et al. 2012). Network theory significantly enhanced our understanding of which collaboration patterns between individuals are favorable to innovative activity within the firm (Allen 1977; Cross and Cummings 2004; Ibarra 1993; Boeddrich and Heinz-Juergen 2004; Tsai 2001; Perry-Smith and Mannucci 2015). Recent literature has vindicated the role of formal structures in an organization, highlighting that someone's formal position in an organization can allow someone to engage in particular activities (better) than others (McEvily et al. 2014). We therefore submit that the network 
position as well as the formal role of an individual both need to be taken into account to understand the antecedents to the voluntary exchange of valuable inputs within an organization.

Network literature assumes that the social structure drives such phenomena as intraorganizational knowledge exchange and has tended to disregard the actual content of what is exchanged (cf. Ensign 2009). Creativity scholars, however, point to perceived value of knowledge that is exchanged as an important indicator of the potential for new knowledge to emanate from the knowledge exchange (Cohen and Levinthal 1990; Amabile, 1996; Smith et al. 2005). Value-of-input exchanged also is a key focus for managers (Zheng 2010; Kratzer et al. 2016). Academic research has neglected to study how the value of inputs exchanged affects social relationships. Since individuals exchange and accumulate knowledge, based on which they create new, innovative knowledge, their subjective valuation of the knowledge that is exchanged is most relevant (Casciaro and Lobo 2015). We define the organization's discretionary social network as the social relations within a firm in which individuals voluntarily discuss new, innovative ideas and knowledge about improvements regarding products and services the organization offers (Rodan 2010; Aalbers et al. 2013). This study examines the effects of what Ockhuysen and Bechky (2009) call a 'simple intervention', building on insights from network research that deals with individuals' network characteristics as predictive of creative outcome as well as on recent insights from creativity scholars that address the importance of perceived value of the content exchanged in relation to the undergirding social infrastructure. We empirically study the actual micro-processes (cf. Foss et al. 2010) management purposefully intervened in. We contribute to the understanding of how managerial intervention affects the voluntarily sharing of new, innovative knowledge in an organization (Zheng 2010; Kratzer et al. 2016). Managerial intervention is central to what managers inside organizations do (Kleinbaum et al. 
2008), yet, surprisingly, the actual effect of an intervention on the inner working of an organization has not been empirically studied using a proper before-and-after research design (Okhuysen and Bechky 2009; Tortoriello 2007; Balkundi and Kilduff 2005). ${ }^{1}$ The particular management intervention was intended to stimulate the sharing of ideation related inputs and focusing on the associated discretionary social network within an organization.The intervention studied here is 'simple' in nature as it differs from more complex interventions - such as downsizing. No formally established organizational configurations were altered (Okhuyzen and Bechky 2009; Fisher 2017).While an intervention may be primarily directed at a specific target population of individuals central to ideation, because of expected benefits of such a focus, it can also affect others. Chuan et al. (2016), for instance, suggest that a managerial intervention aimed at stimulating behavior core to the activities of some individuals may by what they refer to as collective identification enhance what is extra-role behavior for others. Sharing knowledge, even of the tacit kind, is what Chuan et al. (2016) focus on. Following this logic, we differentiate between employees whose primary activity concerns ideation (referred to here as ideators - those employees that are formally part of the NBD operations of the organization) and employees who do not have ideation as their core functional responsibility or capability (referred to here as realizers - those employees formally associated with other functional areas such as IT, operations or marketing). Realizers are only secondarily engaged in the exchange of new, innovative knowledge (cf. Song et al. 2011).

Our study shows that a simple intervention can substantially grow an organization's discretionary social network: employees become significantly more engaged in knowledge

${ }^{1}$ Studies of exogenously engineered network development are rare in general, and restricted to inter-organizational networks (Ahuja et al. 2012; Ferriani et al. 2013; Ozcan and Eisenhardt 2009; Paquin and Howard-Grenville 2013). 
exchange. More importantly, we argue, and find, that the stronger one's position in the discretionary social network prior to an intervention the more valuable ideas one is likely to exchange after a managerial intervention. Dedicated R\&D employees (ideators) are, however, and contrary to our expectations, not more likely to offer more valuable value-of-input after an intervention compared to those who functionally are only secondarily related to innovation (realizers). An intervention can thus make those who earlier were not engaged with ideation become much more involved. Our study thus indicates that, contrary to what is generally believed (Ahuja et al. 2012; Ghosh and Rosenkopf 2014), social networks can change relatively quickly, in unexpected and possibly unintended ways.

\section{Theory and Hypotheses}

Organizations may be seen as places in which individuals display a common purpose and cooperate based on compatible capacities to reach shared objectives (Foss and Lindenberg 2011). An important objective for firms is to be sustainably innovative. Firms that successfully innovate develop and implement more and in particular better ideas than their competitors, gaining competitive advantage (Francis and Bessant 2005). The ability to innovate depends on social interactions to exchange creative and novel ideas between employees of a firm (Bovasso 1996; Perry-Smith and Mannucci 2015). Truly new, innovative knowledge is exchanged in a firm’s discretionary social network - such exchange is largely non-mandated, taking place at the fuzzy front end of the organization’s innovation process (Kijkuit and Van den Ende 2010; Aalbers et al. 2014). A willingness to share innovative knowledge should not be assumed, especially if such knowledge is located in diverse parts of the organization (Aalbers and Dolfsma 2015; Hansen 1999; Reagans and McEvily 2003; Tortoriello and Krackhardt 2010). Exchange of knowledge 
within a company may not occur, even when all involved are aware of the need for it (Szulanski 1996). Managerial intervention may be required to initiate the transfer of innovative knowledge or to stimulate existing activity.

Intervening for ideation. While underexplored in the academic literature, purposive temporary interventions using a taskforce are common in business practice (Okhuysen and Bechky 2009). Little is known about how these interventions actually work, however, as opposed to how they are planned (Agterberg et al. 2010). The ability to proactively intervene as management to spur ideation, however, may help a firm to retain a competitive advantage. What few studies that are available on the effects of management intervention are designed as an experiment under laboratory settings (Okhuysen 2001). The effects of managerial intervention in a real-life setting are likely to differ from that encountered in an experimental setting, however (cf. Bovasso 1996; Okhuysen and Bechky 2009). Yet, the core of what it is that managers do is to intervene in their organization to improve its performance, in particular in relation to knowledge exchange (DeChurch and Marks 2006). The exchange novel, creative knowledge is extra-role, however - management cannot require employees to develop and exchange knowledge that does not exist yet or that management does not know exist in employees (Demerouti et al. 2015). In addition, what is actually transferred cannot directly be controlled, as new knowledge is mostly tacit (Černe, Jaklič and Škerlavaj 2013). While joint knowledge activities may be stimulated, the tacit nature of knowledge may actually constrain how effectively they do so (Chuang et al 2016). In addition, third parties, such as managers and other employees an individual does not directly interact with, may not be able to readily determine the quality or usefulness of new knowledge that is exchanged, even when knowledge is not tacit. 
Employees may not know what knowledge others in the organization have or what knowledge others may need that an employee has (Kijkuit and Van den Ende 2010; Perry-Smith and Mannucci 2015). Management may also not be (fully) aware of the knowledge available to employees in an organization and may thus not be sure how to target an intervention. As a result, the exchange of potentially innovative knowledge can be lower than it would otherwise be (Cooper et al. 1999).

Stimulating exchange of new, creative knowledge may thus be harder for management to stimulate directly (Tagliaventi and Mattarelli 2006; Whelan et al. 2011). Search for and exchange of new ideas, however, certainly benefits from in-role activity to stimulate innovative knowledge exchange formally mandated by management (Whelan et al. 2011; van den Ende et al. 2015). Research has shown that employees who voluntarily display more proactive, extra role behaviors also take more active take part in innovative activity (Ramamoorthy et al. 2005;

Demerouti et al. 2015). Especially during the highly knowledge-intensive, but also informal and possibly erratic fuzzy front end of innovation stands to benefit from employees engaging in discretionary extra-role activity (Lingo and O'Mahony 2010; Van den Ende et al. 2015). Indeed, extra-role behaviors are shown to mediate the relationship between commitment and (innovative) performance (Ramamoorthy et al. 2005; Elorza, Aritzeta and Ayestarán 2011).

Despite these challenges and because of the expected benefits, task-force intervention to encourage employees to search, interact and engage more with others is common practice (Edmondson 2012; Fisher 2017). In an experimental study Okhuysen and Eisenhardt (2002) found that a formal intervention can improve knowledge integration when they create a "window of opportunity" for those targeted by the intervention (Tyre and Orlikowski 1994). A window of opportunity encourages self-awareness and opportunity recognition, as established ways of 
working are reconsidered (Bovasso 1996; Okhuysen 2001; Zellmer-Bruhn 2003). An intervention can cause individuals to shift their focus of attention to others in their environment, and in general stimulates interaction (Okhuysen and Eisenhardt 2002; Zellmer-Bruhn 2003; Logan and Ganster 2007). The creativity literature suggests that encouraging individuals will search for new ideas and perspectives from others when their psychological safety for sharing and experimenting is boosted, also stimulating creative self-efficacy (e.g. Shin et al. 2012; Dong et al. 2017). A formal intervention implemented by management in the form of a small, temporary taskforce facilitating knowledge transfer, may reduce the barriers that limit knowledge integration. Lack of familiarity with others and the knowledge they may have, due to diverse knowledge domains, may be addressed, as may lack of (verbal) skills of some employees or status differences between employees (e.g. Bovasso 1996; Dougherty 1992, Eisenhardt 1989; Szulanski 1996). A simple managerial intervention we define as a set of purposively formulated basic instructions and accompanying facilities to engage in specific behavior, executed by a dedicated temporary taskforce (Okhuysen and Eisenhardt 2002). Okhuysen and Eisenhardt (2002) found that a 'simple managerial intervention' can improve knowledge sharing in an organization and contributes significantly to knowledge integration.

A simple managerial intervention is expected to affect information sharing, questioning of others, and individuals' managing of time (Okhuysen and Eisenhardt 2002). An intervention to stimulate ideation in a firm will first of all highlight the value placed within the firm, by management and employee alike, on new ideas (to be) transferred within the organization. Indeed, research on formal managerial interventions in team formation (Aalbers et al.. 2016; Okhuysen 2001; Okhuysen and Bechky 2009) suggests that stimulate learning and hence performance (Bovasso, 1996; Henry, 1995; Okhuysen 2001; Okhuysen and Eisenhardt 2002; 
Zellmer-Bruhn 2003). Employees already active in the activity targeted by the intervention may seek to be even more active with current partners or engage with more - and new - others in the activity. When, as in this study, the goal of an intervention is to ensure that employees increase the value of the inputs they exchange, we argue below that the value-of-input an employee offers to alters depends on (a) individual's position in the discretionary social network of an organization, and (b) the formal role an individual occupies in the organization. We will argue, below, that the latter should be expected to positively moderate the former.

A. Prior Position in Discretionary Social Network. Individuals may outperform peers if they are better positioned in the social network in which they are embedded (Mehra et al. 2001). Social network literature argues that a larger number of informal relations voluntarily maintained by an individual ensures that one will receive more valuable knowledge input, and will use the valuable input to generate new, innovative knowledge themselves (Bjork and Magnusson 2009; Burt 2004; Kijkuit and Van den Ende 2010; Aalbers et al. 2013). More internal informal communication enhances a firm's innovative performance (Cross and Cummings 2004; Foss et al. 2011). More contacts with others provides access to diverse experiences, unique and varied resources, alternative thought worlds, and complementary functional expertise; it increases one's access to alternative views on a firm's strategy, goals, interests, time horizon, core values (Cross and Cummings 2004; Reagans and McEvily 2003; Ancona and Caldwell 1992; Burt 1992).

By communicating with others, individuals gain access to novel perspectives and unique knowledge and can generate political support for their ideas also indirectly, through their direct contacts. A 'law of large numbers' applies in the context of idea generation: the larger the number of sources of ideas available to an individual, the likelier one is to encounter, combine 
and further develop new ideas (Burt 2004; Ohly et al. 2010). The sheer number of discretionary ties an individual maintains relates to the ability to generate new ideas (Bjork and Magnusson 2009; Ohly et al. 2010; Aalbers et al. 2013). The number of contacts an individual holds also helps in evaluating ideas according to standards valid in a larger social context, such as a firm (Ohly et al. 2010). Although there may be difficulties associated with transferring, integrating, and leveraging the heterogeneous inputs and diverging perspectives if someone maintains many contacts, the diversity of insights enlarges the innovative knowledge base accessed and ideation performance of individuals (Hansen 1999; Tsai 2001; Duncan 1976; Mom et al. 2009; Dougherty 1992; Tortoriello and Krackhardt 2010).

Someone involved with ideation prior to an intervention to stimulate ideation is likely to remain involved after the intervention. The legitimacy of ideation related activity is heightened within the organization. Someone well-connected in an discretionary social network, maintaining many ties, receives diverse and valuable input. Since the window of opportunity to develop ideation activities increases, a well-connected individual will have more valuable knowledge than others, some of which he shared and some of which he might not have shared. An intervention to stimulate ideation will entice such a well-connected individual to share more knowledge, to more individuals. An intervention to stimulate ideation will increase the perceived value of all ideation-relevant information and knowledge, but for some knowledge this is likely to be the case more. The knowledge that well-connected individuals have is likely to be perceived as more valuable as a result of the intervention, because such individuals are more likely to provide relevant and properly weighted input for ideation (Cattani et al. 2008, Uzzi and Spiro 2005). Even before the intervention well-connected individuals have more valuable 
knowledge to exchange than others, and the intervention makes such knowledge more valuable still.

While there are costs associated with maintaining many relations and the number of contacts cannot increase indefinitely, we assume that this limit is not within reach for many or all employees in most organizations. This gives rise to our first hypothesis:

H1: The larger the number of direct ideation ties maintained by an individual before a managerial intervention, the higher the value-of-input attributed to this individual after the intervention.

We need to separate out the effect of the intervention stimulating ideation, which will increase the number of ties in the discretionary social network for everybody involved, from the effect of the intervention on the increase in the Value-of-input exchanged in the discretionary social network. We thus include the increase in the number of ties in the discretionary social network due to the intervention [from $\mathrm{t}=1$ to $\mathrm{t}=2$ ] as a control.

B. Moderation: Ideators and realizers. An intervention to stimulate ideation in a firm will first of all highlight the value placed within the firm, by management and employee alike, on new ideas conducive to innovation transferred in the discretionary social network. Employees already whose primary activity concerns ideation, ideators, are already very active in the discretionary social network before the intervention. There are also individuals whose primary activity is not ideation, realizers. Ideators will in particular seek to share knowledge relevant for ideation more actively because of the intervention, and particularly those pieces that are valuable, because of 
how core ideation is to their activities. Ideators will be vindicated by the added value placed on ideation (Song et al. 2011). Ideators are more likely to have knowledge that is relevant for ideation than realizers. Realizers are likely to have knowledge to offer for ideation that was already previously available or considered. Even before an intervention they had volunteered to be involved with ideation, offering what knowledge is relevant. Ideators are likely to already have approached those realizers they needed for idea development before an intervention as well. Ideators are more likely to have (had) ideas that they did not (yet) share with colleagues but that an intervention enticed them to (start) sharing. A successful intervention encourages both ideators and realizers to be more actively engaged in the discretionary social network, offering more and more valuable knowledge than before. Realizers are, however, more likely to have already brought in what knowledge they had that was relevant for ideation than ideators. For realizers, ideation knowledge is a smaller share of the knowledge that they work with. Realized were already mostly voluntarily involved with ideation before an intervention; they were not tasked to do so in the way that ideators were.

Because of the higher value of innovative knowledge inputs that ideators can offer in the discretionary social network, compared with realizers, they are able to leverage their position in the network better. If a well-connected individual in the discretionary social network is an ideator, that person is likely to be perceived as providing more valuable innovative knowledge to begin with, and also likely to see the value attributed to her knowledge increase because of the intervention. The intervention highlights the value of knowledge and expertise that ideators have in particular, stimulate interest in knowledge sharing with these employees.

Certainly, maintaining knowledge exchange relations can be costly in terms of effort and time spent. Sharing new, innovate knowledge is likely to be costly because it often is complex 
and tacit, and individuals may consider hoarding knowledge rather than sharing it (Lam and Lambermont-Ford 2010). Communication costs employees face when transferring new, innovative knowledge are lowered by purposive temporary intervention (Levine and Prietula 2011; Haas and Hansen 2005; Tsai 2000). The costs of sharing new, innovative knowledge may in addition differ by type of employee, however. Creators, involved in innovation before the intervention, have established contacts for exchange of new innovative knowledge. They are also more used to exchange of such knowledge. Realizers, not primarily involved in innovation activities before the intervention and focused on the more mundane 'going-ons' in the organization, are less likely to have an innovation network available to them prior to intervention and are less experienced at exchanging new, innovative knowledge. Realizers thus face higher costs when establishing new contacts in the social network where new, innovative knowledge is exchanged.

Hence, fulfilling an ideator role is likely to stronger enhance the positive effect of being well-connected in the discretionary social network on the value-of-input provided after an intervention as compared to realizers. We thus suggest the following moderation hypothesis:

H2: The positive effect of being well-connected in the discretionary social network on the value-of-inputs provided after an intervention, is likely to be higher for ideators (compared to realizers) [positive moderation].

As before, we need to distinguish the effect of the intervention stimulating value-of-input from an increase in the number of ties in the discretionary social network for individual employees. 
We therefore include increase in the number of ties in the discretionary social network, interacted with ideator (role), as a control variable.

The argument we develop can be presented in the following conceptual model (Figure 1):

\section{- $\quad$ Figure 1 here -}

\section{Methods}

Beta Company. This study was carried out at Beta Company (a pseudonym), one of Europe's largest and most innovative payment processors, leading the market for payments and card processing solutions. The company employs 1500 employees. Observation at Beta Company began during May 2009, coinciding with the first measurement round of network data.

We observed the ideation community prior to, during and after the intervention of the establishment of Taskforce $\mathrm{Y}$ at Beta Company, gathering evidence on the effect of this managerial intervention on the social structure of the organization. The managerial intervention involved the deployment of a dedicated taskforce to enhance ideation by increasing the relations in the ideation community through awareness creation (cf. Okhuysen and Eisenhardt 2002). The intervention was driven by the recent desire of the top management team to be a leading innovative player amongst its competitors, constituting a strategic shift for a company that had been competing primarily on operational efficiency in the prior decade while exploring innovation only as a secondary intent. The focus of the intervention was to enhance the networking activities of the established, early hour ideation community, at $t=1$. While seeking to increase cooperation in the discretionary social network, the intervention - internally framed as an initial exploratory pilot to realign strategy with operational practice - operated in an indirect 
manner by arranging formal and informal meetings, in effect using the formal and informal aspects of the organization. Framed as a field study we take the concept of managerial intervention out of the experimental laboratory setting in which it has been commonly studied (e.g. Okhuysen and Eisenhardt 2002), into a real life company. Obviously, however, randomly assigning employees to undergo the intervention while assigning a second part a control condition is not an option - enhanced realism may thus come at the expense of decreased possibilities for causal inference (c.f. Burkhardt and Brass 1990). In this method section we try to indicate how we tried to combine these two research concerns as much as possible.

A 'Simple' (Taskforce) intervention. We observe the impact of the taskforce that is tasked to enhance the awareness of the relevance of networking activities related to ideation, stimulating individuals to share more information. The taskforce intervention - simple by the Okhuyzen and Bechky (2009) definition - brings individuals together on a voluntary basis, organizing intra-organizational networking activities related to ideation. The taskforce, for instance, offered to introduce individuals to others within the organization and facilitate the exchange that could result. In the process, the taskforce members pointed out opportunity, critically queried employees on their daily routines, and suggested on the management of time and tasks so that involvement in the ideation community may be enhanced. Exploratory in nature, the managerial intervention consisted of a taskforce operative for a relatively short period of two months, staffed by a senior and a mid-level employee, both of whom could allocate the majority of their time to implementing the intervention. Each of the task force members was well-connected throughout the organization. Notably, the intervention targeted all employees constituting the ideation community at time $\mathrm{t}=1$ (ideators and realizers). The intervention took place over a period of two months, with measurement post intervention taking place after 6 
months, allowing the intervention to settle in the organization. The target population was jointly determined by management and taskforce members. The intervention was introduced in a general kick-off meeting, and was recurrently brought under employees’ attention in bilateral and team meetings to emphasize the relevance of enhanced cooperative behavior for both the ideation community as a whole as for the individual. The taskforce contacted the ideation community at $\mathrm{t}=1$ as to explain the purpose of the intervention and the activities that could be undertaken. To rule out other factors that could offer an alternative explanation for the changes in the network for innovative knowledge transfer we observe, we enquired about the degree to which other developments in the firm could account for changes in the ideation community at Beta Company (number and diversity of ties). Following Okhuysen and Eisenhardt (2002) we include the larger organizational context in our interpretation of the effects of the managerial intervention at Beta Company. In the period between $\mathrm{t}=1$ and $\mathrm{t}=2$ no other internal or external change agents (internal projects or task forces, nor external advisors) were active. Management at Beta Company stressed the relevance of focused and piecemeal action to assure maximal effect when it comes to strategic initiatives. Hence, no other managerial intervention was mandated, nor formal change program carried out in the three months period before $t=1$. No new ideation projects had formally started in the period of observation. In general, no corporate initiatives pushing networking activities that were not part of the intervention were identified. Additionally, interviews with various stakeholders within the organizations, representing both upper and lower echelon employees as well as representatives from all major departments, were carried out to verify if any informal events or changes in the external environment (e.g. market incentives, recently entered new markets, recently acquired clients, new governmental ideation policy or ideation grants etc.) had taken place that might offer an alternative account for changes 
observed in the ideation community. None of this appeared to be the case. All stakeholders interviewed clearly stated that the taskforce indeed had been successful in stimulating the ideation community to grow and become more active, and that other events could not offer an explanation for this.

Data Collection. In social network studies the most pragmatic approach in an organizational setting is believed to be the survey methodology (Borgatti and Cross 2003; Wasserman and Faust, 1994). Following prior work in the context of intra-organizational networks dedicated to the transfer of innovative knowledge, this study deploys snowball methodology as the basis for this survey (Borgatti and Cross 2003; Henttonen 2010; Aalbers et al. 2013). Snowball sampling is especially useful when the target population is not clear from the beginning (Wasserman and Faust, 1994), which is the case for an ideation community. Snowball sampling is based upon several rounds of surveying or interviewing where the first round helps to determine who will be approached as a respondent in the second round, and so on. The first round of snowball sampling can be totally at random but it can be also based on specific criteria (Rogers and Kincaid, 1981). To reduce the risk of ignoring 'isolates', i.e. isolated persons within the organization who do possess relevant knowledge to a particular subject, but who are being left out by the study due to the lack of accuracy of random sampling (Rogers and Kincaid, 1981), this study opted in a first round to target respondents selected in collaboration with new business development management. The target population then emerged in several rounds of surveying, where contacts mentioned in a round determine who should be approached as a respondent in a subsequent round.

Snowball sampling procedure was applied at both $\mathrm{t}=1$ and $\mathrm{t}=2$. For the first round, all 27 employees involved in the New Business Development (NBD) unit, those most involved in the 
ideation community, and referred to here as creators, were approached. All filled in the questionnaire. Names of those involved with the transfer of new, innovative knowledge were validated by the manager of the NBD unit as well as by the heads of the other units involved with ideation activity where realizers are based. The second round of targeted respondents received the survey by email or was interviewed. At $t=1$ this resulted in the identification of 181 individuals. Our overall response rate at $\mathrm{t}=1$ was $95 \%$ percent. Based on a similar procedure our overall response rate at $\mathrm{t}=2$ was $92 \%$ (241 individuals in the ideation community).

Interviews we conducted (we conducted interviews with 21 individuals before, during and after the intervention) served three purposes: first, to become familiar with the organization, second, to serve as the first round in our snowball sampling procedure and, third, to place our quantitative findings in the appropriate qualitative context. In addition, data were gathered by observing taskforce activities on a regular basis during the entire period. Data on the nonrelational and relational elements of the taskforce were assembled by noting the activities of the taskforce members, by interviewing the members and by asking taskforce members to write up the activities and their perception of the effect of the intervention. Observations of actions and interactions were supplemented by data drawn from the interviews and questionnaire and from company records.

An online survey was chosen to reduce the time needed to complete the questionnaire, thus improving response rates. Respondents were invited to participate in the research by means of a personalized e-mail. The email hyperlinked to an online survey that contained to start with personalized letter and a description of the research project including instructions to complete the survey. Email and letter were endorsed and co-signed by the senior new business development manager to improve response rates. To reduce ambiguity regarding the interpretation of the 
questions by the respondents, the network questions were formulated in the native language - in this case Dutch and English.

Independent Variable. Following Each individual in the population was asked about their contacts for the exchange of new ideas, ideations and substantial improvements to products and services that are not part of their day-to-day activities in the last 3 months (Aalbers et al. 2013, 2014; Cross and Prusak 2002; Rodan 2010; Smith et al. 2005). To ensure that respondents were clear about the nature of the contacts we asked them to report on, we additionally and explicitly asked respondents to report on their workflow relations, or those relations maintained to carry out their daily work routines. Respondents' correct understanding of the contact they were asked to provide was ascertained via exploratory interviews during the pilot phase and the actual surveying The exact name generation items for both these types of contacts are reported as Appendix 1. We did not fix the number of contacts a respondent could mention by using a (dropdown) list of names provided by management or by indicating a limit to the number of possible contacts a respondent could list (Friedman and Podolny, 1993). However, we did suggest naming six employees in order to make sure that individuals mentioned their most important contacts.

Following Freeman (1979) and Tsai (2001), we use in-degree centrality or number of contacts reported by the alters of an ego, since it is the most suitable measure to characterize if ego's position in a network allows them to access information and knowledge. Bjork and Magnusson (2009) point out that in-degree centrality is the most appropriate measure in the context of early stage idea generation. In-degree centrality is a stable (Costenbader and Valente 2003) and reliable measure since it does not rely on self-reporting (Casciaro 1998; Carley and Krackhardt 1996). We calculated egos' in-degree centrality pre- and post-intervention. To determine the effect of the managerial intervention change over time, based on a pre- and post- 
event research design, the delta of or difference in the number of ideation ties between $\mathrm{t} 1$ and $\mathrm{t} 2$ was calculated. These are referred to as delta ties $\left(\Delta \mathrm{t}_{1}\right.$ to $\left.\mathrm{t}_{2}\right)$ and were calculated for the 151 employees involved in the network for innovative knowledge transfer at both $\mathrm{t}=1$ and $\mathrm{t}=2$.

Dependent Variable. Value-of-input measures the peer-assessed value of the ideation inputs provided by an individual (Levin and Murnighan 2010), because, “[a] knowledge seeker is the best, perhaps the only, judge of the usefulness of knowledge received" (Levin and Cross 2004, p.1482).

In line with recent network research on the instrumental value of inputs exchanged (Casciaro and Lobo 2015), we asked respondents about the subjective value they attribute to the inputs provided by each of their reported ideation ties on a single item 7 point Likert scale (a value of 1 representing no value ascribed by receiver to the content exchanged, and a value of 7 reporting input received to be exceptionally high to the recipient). Value-of-input for a sender, as reported by receivers, is averaged to measure what value their inputs constitute (cf. Ensign 2009). This is measured both before and after the intervention; the measurement before the intervention is included as a control variable (see below).

Moderator Variable. Additionally, ideator $(\mathrm{Y} / \mathrm{N})$ is included as a binary variable to control for the functional orientation or role of the individual employees engaged with ideation. The variable differentiates between employees whose prime functional capability and role is ideation, ‘ideators', and 'realizers'. Employees who do not have ideation as a core functional capability but are nonetheless involved with ideation are here referred to as realizers (cf. Song et al. 2011). The descriptive statistics presented additionally identify newcomers, individuals that join the discretionary social network after the intervention. All newcomers are 'realizers', not 
primarily but only secondarily involved with ideation - no additional formal ideation roles were created by the organization from $t=1$ to $t=2$. Newcomers are not included in the statistical analysis since no data was available about them at $\mathrm{t}=1$.

Control Variables. Tenure (in months), gender and hierarchical level, and value-ofinput provided at $\mathbf{t}=\mathbf{1}$ were included as controls. We included tenure to control for the possibility an individual has had to develop relations over time (Gundry 1993). Gender and hierarchical level ensure control for group affiliation effects.

We test our hypotheses by applying OLS modeling. Our models are estimated using the statistical package “R” (version 3.0.1).

\section{Results}

Descriptive statistics. Table A1 in the appendix presents descriptive statistics, while Figure 2 provides visual representation of the changes in the discretionary social network at Beta Company between $\mathrm{t}=1$ and $\mathrm{t}=2$. The ideation community at Beta Company certainly increased in size (see also Table 1) and also became increasingly active (Table 3) due to the intervention. One could also claim, as a creator did at $\mathrm{t}=1$, that there was a dire need for improvement: “involvement with ideation is poor, we are truly wasting potential. Communication between NBD and the rest of the organization is at a low."

\section{- Table 1 here -}

- $\quad$ Figure 2 here - 
Regression results. Descriptive statistics, presented in Table 1, show a substantial increase in the number of ties due to the intervention. Taking into account the effect of organizational attrition, 139 individuals were eventually involved with networking activities related to ideation at both $t=1$ and $t=2$. For this group of 139 individuals, activity in the network for innovative knowledge transfer can be statistically compared over time to assess the effects of the intervention in relation to what Hypotheses 1 and 2 predict. Prior to conducting the regression analyses, variables were examined for homoscedasticity and for non-normal distributions. The outcomes showed no violation of the normality assumption. Table 2 presents the results for each of the linear regression models that test for Hypotheses 1 and 2. Interviews we had prior to the survey indicated initial support for both hypotheses. Worded in negative terms, one manager (realizer) claimed: "Communication regarding new ideas and services is exceedingly slow and centered around elite groups. What should be improved is discussed and developed by an incrowd. Choices concerning ideation are made without involving relevant outsiders.”

Table 2 shows what determines which individuals will offer input to others that is perceived as highly valuable, indeed more valuable than before an intervention. In line with the argument in support of our hypothesis 1, being well connected - in terms of number of direct ties -- in the discretionary social network before an intervention will ensure that one is likely to increase the perceived value of what one offers after the intervention (Model 4: $\mathrm{b}=0.38, p$ $<0.001)$. The increased perceived value-of-input is not due to the increase in the number of ties in the discretionary social network, as this effect is taken into account separately. We thus find strong support for our hypothesis 1.

While the value-of-input that ideators offer is perceived to be high, and increases due to the intervention of a taskforce (Model 4: $\mathrm{b}=3.17, p<0.001$ ), ideators do not seem to be able to 
leverage a strong position in the discretionary social network (Model 4: $\mathrm{b}=-0.31, p<0.001$ ). We thus need to reject hypothesis 2. While this result cannot be considered as support for the assertion that, alternatively realizers indeed are better able to leverage their position in an discretionary social network. Still, qualitative data suggests that it might. One realizer, for instance, stated: "I appreciate the increased buzz surrounding the topic of ideation. And honestly it is the enthusiasm of my colleagues that made me realize that there are things to be gained here, even though I am not directly responsible for innovative output, that is."

\section{- $\quad$ Table 2 here -}

\section{Discussion, Conclusion and Limitations}

When firms change strategy they may have to change the shape or size of their organization. Management may seek to stimulate involvement of employees in innovation activities by purposeful intervention (Diehl and Stroebe 1987; DeChurch and Marks 2006). Surprisingly, little is known, however, about the effects of managerial intervention in general, and on knowledge exchange and innovative activities in particular (Okhuysen and Bechky 2009). This study investigates the effects of a 'simple managerial intervention' by management to stimulate innovative knowledge sharing among employees at a large European financial service provider. In particular, we determine what antecedents make individuals share more valuable innovation inputs.

We find, in line with Hypothesis 1, that a taskforce intervention can significantly improve the perceived value and quality of knowledge exchange in the discretionary social network, the 
network where new, innovative ideas and knowledge for improvements for products and services the organization offers are exchanged (Rodan 2010; Aalbers et al. 2013). Employees who are well connected in terms of amount of direct relations in the discretionary social network, in which individuals' involvement is largely discretionary, prior to intervention will provide valueof-input to others that is higher following an intervention. Thus, merely highlighting the importance of ideation and innovation to a firm stimulates employees to be more active as well as for individuals to provide higher value-of-input in the discretionary social network to others.

Hypothesis 2, which conceptually and managerially seemed intuitive, must be rejected. Contrary to expectations, employees tasked with ideation will not be able to leverage their favorable (central) position in the discretionary social network more, providing further increased value-of-input as a result of a managerial intervention. There is no such positive moderation. This unexpected finding should open up further research about the effect of having individuals in a firm adopt particular roles to support ideation and innovation (cf. Aalbers and Dolfsma 2015b) and about the effect of formal structure on an organization's performance (McEvily et al. 2014). Specialization in a firm by giving individuals in particular roles specific tasks might make employees perform better overall, but in some ways roles might also prevent improvements in some areas or might prevent the organization from adjusting to changing circumstances as well. The intervention enhanced the overall engagement of employees across the spectrum with innovation activities. We offer the suggestion that the intervention might have brought together polar opposite groups in the organization. Realizers might before have refrained from contributing perhaps to the detriment of what ideators, potentially perceived before as an elite group, could deliver before the intervention. More research is needed to determine under what conditions individuals in ideator roles will also contribute more valuable input, but are unable to 
leverage a strong position in this discretionary social network. Perhaps these employees lack 'strategic linking capability' in the larger organization (Tsai 2000, 2001).

While we may not unproblematically generalize our findings, this study does offer a number of contributions to the broader management literature. Our study contributes, first of all, to work by Ahuja and others on network evolution (Ahuja et al. 2012; Gosh and Rosenkopf 2014). Targeted intervention by management, we find, can change the networked interactions (related to ideation) within a firm (cf. Kijkuit and Van den Ende 2010). The few studies that consider the network consequences of targeted intervention focus on structural characteristics, with little concern for individuals’ voluntary network behavior (Burkhardt and Brass 1990; Shah 2000; Ghosh and Rosenkopf 2014). Involvement in the discretionary social network being largely voluntary, the evolution of this network is likely to differ from that of the formal, workflow network. Yet, many employees in our case study have changed their behaviors, voluntarily increasing both the number of ties in the discretionary social network as well as offering increased value-of-input, without the guarantee of a return (cf. Van der Eijk et al. 2009). Value-of-input and the number of alters an individual is connected to can ultimately meet with decreasing and possibly negative returns, but such reduced effects may not set in soon. There thus is substantial room to improve ideation activity in the very short term with little investment by management. Tapping into the ideation potential available in a firm as a whole, beyond the group of ideators, may, however, only be possible if a core group of ideators is present to begin with. There is, thus, a need for additional research studying the development of discretionary social network structures over time (cf. Kijkuit and Van den Ende 2010; Aalbers and Dolfsma 2015a), including as a result of managerial intervention. 
Our research is of an exploratory nature and as such has a number of limitations. We would like to mention three at this stage, acknowledging that there might be more. First, we looked at an intra-organizational network within a single firm. We believe that our findings are generalizable to other firms (cf. Aalbers et al. 2014), however, but further research must confirm this (see Siggelkow 2007). Cross-sectional data analysis using network data is infeasible (Aalbers and Dolfsma 2015a): intervention by the management of one firm will not affect the employees of another. The effectiveness of a managerial intervention would, however, clearly seem to depend on various organizational factors such as corporate culture and how the intervention is related to prior improvement initiative, for instance. In this study, the observed taskforce intervention was a new and original initiative, yet organizations that recently underwent or simultaneously undergo multiple interventions may react differently. Prior research for instance has shown that repetitive unsuccessful managerial interventions harm employee morale and knowledge retention at the firm level (Cascio 2005; Fiedler and Welpe 2010). Secondly, the study of the effects of an intervention in a real business setting did not allow us to include an appropriate control group. Thus, we could not identify and study a group of employees who were not exposed to the changed social infrastructure (cf. Burkhardt and Brass 1990). Furthermore, understanding the specific social dynamics through which a simple managerial intervention influences knowledge sharing between individuals will be advanced by future research that focuses on the cognitive mechanisms that may drives such processes. This study thus is not a genuine experimental study, which would allow for clearer identification of causal relations. Experiments are conducted with participants and in settings that are, however, less realistic. Our study may thus be relatively strong in external validity while its internal validity may be in need of improvement. Thirdly, no data was available to measure the ultimate 
innovation outcomes of networking activity related to ideation at the individual, the unit or the firm level.

\section{References}

- Aalbers, Hendrik L., and Wilfred Dolfsma. 2015a. Innovation Networks - Managing the networked firm. London \& New York: Routledge.

- Aalbers, Hendrik L., and Wilfred Dolfsma. 2015b. "Bridging Firm-Internal Unit Boundaries for Innovation: Communication Orientation and Brokering Roles.” Journal of Engineering and Technology Management 36(April): 97-115.

- Aalbers, Hendrik L., Wilfred A. Dolfsma, and Otto Koppius. 2014. "Rich Ties and Innovative Knowledge Transfer within a Firm.” British Journal of Management 23: 96-109.

- Aalbers, Hendrik L., Wilfred A. Dolfsma, and Otto Koppius. 2013. “Individual Positioning in Innovation Networks: On the Role of Individual Motivation.” Research Policy 42: 624-34.

- Ahuja, Gautam, Giuseppe Soda, and Akbar Zaheer. 2012. “The Genesis and Dynamics of Organizational Networks.” Organization Science 23: 434-48.

- Agterberg, L. C. Marlous, Bart J. van den Hooff, Marleen H. Huysman, and Maura Soekijad. 2010. “Keeping the Wheels Turning: The Dynamics of Managing Networks of Practice.” Journal of Management Studies 47: 85-108.

- Allen, Thomas J. 1977. Managing the Flow of Technology. Cambridge, MA: MIT Press.

- Ancona, Deborah G., and David F. Caldwell. 1992. "Bridging the Boundary: External Activity and Performance in Organizational Teams.” Administrative Science Quarterly 37: 634-65. 
- Björk, Jennie, and Mats Magnusson. 2009. "Where Do Good Innovation Ideas Come From? Exploring the Influence of Network Connectivity on Innovation Idea Quality.” Journal of Product Innovation Management 26: 662-70.

- Blundell, Richard, Rachel Griffith, and John Van Reenen. 1999. "Market Share, Market value and Innovation in a Panel of British Manufacturing Firms.” Review of Economic Studies 66: 529-54.

- Boeddrich, Heinz-Juergen. 2004. “Ideas in the Workplace: A New Approach Towards Organizing the Fuzzy Front End of the Innovation Process.” Creativity and Innovation Management 13: 274-85.

- Borgatti, Steve, and Rob Cross. 2003. "A relational view on information seeking and learning in social networks.” Management Science 49 (4): 432-45

- Bovasso, Gregory. 1996. “A Network Analysis of Social Contagion Processes in an Organizational Intervention.” Human Relations 49: 1419-35.

- Burkhardt, Marlene E., and Daniel J. Brass. 1990. “Changing Patterns or Patterns of Change: The Effect of a Change in Technology on Social Network Structure and Power.” Administrative Science Quarterly 35: 104-27.

- Burt, Ronald S. 1992. Structural Holes. Cambridge, MA: Harvard UP.

- Burt, Ronald S. 2004. "Structural holes and good ideas.” American Journal of Sociology 110(2): 349-99

- Campbell, A, Whitehead, J., Alexander, M, and Goold, M. 2014, Strategy for the Corporate Level: Where to Invest, What to Cut Back and How to Grow Organisations with Multiple Divisions, 2nd Edition, Jossey-Bass, Wiley 
- Carley, Kathleen M., and David Krackhardt. 1996. “Cognitive Inconsistencies and NonSymmetric Friendship.” Social Networks 18: 1-27.Casciaro, Tiziana and Miguel S. Lobo. 2015. “Affective primacy in intraorganizational task networks” Organization Science 26(2): 373-389.

- Casciaro, Tiziana. 1998. "Seeing Things Clearly: Social Structure, Personality, and Accuracy in Social Network Perception.” Social Networks 20: 331-51.

- Cascio, Wayne F. 2005. “Strategies for Responsible Restructuring.” Academy of Management Executive 19(4): 39-50.

- Černe, M., Jaklič, M., and Škerlavaj, M. 2013. "Management innovation in focus: The role of knowledge exchange, organizational size, and IT system development and utilization.” European Management Review 10(3): 153-166

- Chaney, Paul K., and Timothy M. Devinney. 1992. "New Product Innovations and Stock Price Performance. “ Journal of Business Finance \& Accounting 19: 677-95.

- Chuang, C. H., Jackson, S. E., and Jiang, Y. 2016.. Can knowledge-intensive teamwork be managed? Examining the roles of HRM systems, leadership, and tacit knowledge. Journal of Management 42(2): 524-554.

- Cooper, Robert G., Scott J. Edgett and Elko Kleinschmidt. 1999. “New Product Portfolio Management: Practices and Performance.” Journal of Product Innovation Management 16(4): 333-351.

- Costenbader, Elizabeth, and Thomas W. Valente. 2003. “The Stability of Centrality Measures When Networks Are Sampled.” Social Networks 25: 283-307.

- Cross, Rob, and Jonathon N. Cummings. 2004. “Tie and Network Correlates of Individual Performance in Knowledge Intensive Work.” Academy of Management Journal 47: 928-37. 
- Cross, Rob, and Laurence Prusak. 2002. “The People Who Make organizations Go- or Stop.” Harvard Business Review 80: 104-12.

- Cross, Rob, Stephen P. Borgatti, and Andrew Parker. 2002. "Making Invisible Work Visible: Using Social Network Analysis to Support Strategic Collaboration.” California Management Review, 44: 25-46.

- DeChurch, Leslie A., and Michelle A. Marks. 2006. "Leadership in Multiteam Systems.” Journal of Applied Psychology, 91: 311-29.

- Demerouti, E., Bakker, A. B., and Gevers, J. M. 2015. “Job crafting and extra-role behavior: The role of work engagement and flourishing.” Journal of Vocational Behavior, 91: 87-96.

- Diehl, Michael, \& Stroebe, Wolfgang. 1987. Productivity loss in brainstorming groups: Toward the solution of a riddle. Journal of Personality and Social Psychology, 53(3): 497509.

- Dong, Yuntao, Bartol, Kathryn M., Zhang, Zhi-Xue., and Li, Chenwei. 2017. "Enhancing employee creativity via individual skill development and team knowledge sharing: Influences of dual-focused transformational leadership.” Journal of Organizational Behavior 38(3): 439-458.

- Dougherty, Deborah. 1992. “Interpretive Barriers to Successful Product Innovations in Large Firms.” Organization Science 3: 179-202.

- Duncan, Robert B. 1976. “The Ambidextrous Organization.” In The Management of Organization, edited by Ralph H. Kilmann, Louis R. Pondy, and Dennis P. Slevin. New York: North-Holland.

- $\quad$ Edmondson, Amy C. 2012. "Teamwork on the Fly." Harvard Business Review 90(4): 72-80. 
Eisenhardt, Kathleen M. 1989. "Building Theories from Case Study Research.” Academy of Management Review 14: 532-50.

Elorza, Unai, Aritzeta, Aitor, and Ayestarán, Sabino. 2011. “Exploring the black box in Spanish firms: the effect of the actual and perceived system on employees' commitment and organizational performance.” International Journal of Human Resource Management 22(7): 1401-22.

- Ensign, Prescott C. 2009. Knowledge Sharing among Scientists. New York: Palgrave Macmillan.

- Ferriani, Simone, Fabio Fonti, and Raffaele Corrado. 2013. "The Social and Economic Bases of Network Multiplexity: Exploring the Emergence of Multiplex Ties.” Strategic Organization 11: 7-34.

- Fiedler, Marina, and Isabell Welpe. 2010. "How Do Organizations remember? The Influence of Organizational Structure on Organizational Memory.” Organization Studies 31: 381-407.

- Fisher, Colin M. 2017. “An ounce of prevention or a pound of cure? Two experiments on inprocess interventions in decision-making groups.” Organizational Behavior and Human Decision Processes 138: 59-73.

- Foss, Nicolai J., Kenneth Husted, and Snejina Michailova. 2010. “Governing Knowledge Sharing in Organizations.” Journal of Management Studies 47: 455-82.

- Foss, Nicolai J., and Siegwart Lindenberg. 2011. “Managing Joint Production Motivation.” Academy of Management Review 36: 500-25.

- Foss, Nicolai J., Keld Laursen, and Torben Pedersen. 2011. “Linking Customer Interaction and Innovation: The Mediating Role of New Organizational Practices.” Organization Science 22: 980-99. 
- Francis, David and John Bessant. 2005. “Transferring Soft Technologies.” International Journal of Sustainable Technology and Development 4: 93-112.

- Freeman, Linton C. 1979. “Centrality in Social Networks.” Social Networks 1: 215-39.

- Friedman, Raymond A., and Joel Podolny. 1992. "Differentiation of Boundary Spanning Roles: Labor Negotiations and Implications for Role Conflict.” Administrative Science Quarterly 37: 28-47.

- Ghosh, Anindya, and Lori Rosenkopf. 2014. "Shrouded in Structure: Challenges and Opportunities for a Friction-Based View of Network Research.” Organization Science 26: 622-31, doi:10.1287/orsc.2014.0922.

- Goodwin, Vicki L., W. Matthew Bowler, and J. Lee Whittington. 2009. “A Social Network Perspective on LMX Relationships.” Journal of Management 35: 964-80.

- Gulati, Ranjay. 1995. "Social Structure and Alliance Formation Patterns: A Longitudinal Analysis.” Administrative Science Quarterly 40: 619-52.

- Gundry, Lisa K. 1993. "Fitting into Technical Organizations: The Socialization of Newcomer Engineers.” IEEE Transactions on Engineering Management 40: 335-45.

- Haas, M. R., and Morten T. Hansen. 2005.” When using knowledge can hurt performance: The value of organizational capabilities in a management consulting company”. Strategic Management Journal, 26(1), 1-24.

- Hansen, Morten T. 1999. “The Search-Transfer Problem: The Role of Weak Ties in Sharing Knowledge across Organization Subunits.” Administrative Science Quarterly 44: 82-111.

- Henttonen, Kaisa. 2010. "Exploring Social Networks on the Team Level - A Review of the Empirical Literature.” Journal of Engineering and Technology Management 27: 74-109. 
- Human, Sherrie E., and Keith G. Provan. 2000. “Legitimacy Building in the Evolution of Small-Firm Multilateral Networks: A Comparative Study of Success and Demise.” Administrative Science Quarterly 45: 327-65.

- Ibarra, Herminia. 1993. “Network Centrality, Power and Innovation Involvement.” Academy of Management Journal 36: 471-501.

- Ibarra, Herminia. 1995. "Race, Opportunity, and Diversity of Social Circles in Managerial Networks.” Academy of Management Journal 38: 673-703.

- Katila, Riitta, and Gautam Ahuja. 2002. "Something Old, Something New: A Longitudinal Study of Search Behavior and New Product Introduction.” Academy of Management Journal 45: 1183-94.

- Kijkuit, Bob, and Jan van den Ende. 2010. "With a Little Help from Our Colleagues: A Longitudinal Study of Social Networks for Innovation.” Organization Studies 31: 451-79.

- Kratzer, Jan, Lettl, Christopher, Franke, Nikolaus, \& Gloor, Peter. A. 2016. “The social network position of lead users.” Journal of Product Innovation Management 33(2): 201-216.

- Lam, Alice, \& Lambermont-Ford, Jean-Piere. 2010. “Knowledge sharing in organisational contexts: a motivation-based perspective.” Journal of Knowledge Management, 14(1): 51-66.

- Levin, Walter, and Murnighan. 2010. "Dormant Ties: The Value Of Reconnecting” Organization Science 22(4), pp. 923-939.Levine, S. S., \& Prietula, M.J. 2012. “How knowledge transfer impacts performance: A multilevel model of benefits and liabilities.” Organization Science 23(6): 1748-1766.

- Logan, Mary S., and Daniel C. Ganster. 2007. "The Effects of Empowerment on Attitudes and Performance: The Role of Social Support and Empowerment Beliefs.” Journal of Management Studies 44: 1523-50. 
- McEvily, Bill, Giuseppe Soda and Marco Tortoriello. 2014. "More Formally: Rediscovering the missing link between formal organization and informal social structure” Academy of Management Annals 8(1): 299-345.

- Mehra, Ajay, Martin Kilduff, and Daniel J. Brass. 2001. The social networks of high and low self-monitors: Implications for workplace performance. Administrative Science Quarterly 46 (1): 121-146

- Mom, Tom J. M., Frans A. J. Van Den Bosch, and Henk W. Volberda. 2009. “Understanding Variation in Manager's Ambidexterity: Investigating Direct and Interaction Effects of Formal Structural and Personal Coordination Mechanisms.” Organization Science 20: 812-28.

- Ohly, Sandra, Robert Kase, and Miha Škerlavaj. 2010. "Networks for Generating and Validating Ideas.” Innovation: Management, Policy and Practice 12: 50-60.

- Okhuysen, Gerardo A. 2001. "Structuring Change: Familiarity and Formal Interventions in Problem- Solving Groups.” Academy of Management Journal 44: 794-808.

- Okhuysen, Gerardo A., and Beth A. Bechky. 2009. "Coordination in Organizations: An Integrative Perspective.” Academy of Management Annals 3: 463-502.

- Okhuysen, Gerardo A., and Kathleen M. Eisenhardt. 2002. “Integrating Knowledge in Groups: How Formal Interventions Enable Flexibility.” Organization Science 13: 370-86.

- Paquin, Raymond L., and Jennifer Howard-Grenville. 2013. "Blind Dates and Arranged Marriages: Longitudinal Processes of Network Orchestration.” Organization Studies 34: 1623-53.

- Perry-Smith, Jill and Pier V. Mannucci. 2015 "From creativity to innovation: The social network drivers of the four phases of the idea journey” Academy of Management Review, forthcoming. 
- $\quad$ Ramamoorthy, Nagarajan, Flood, Patrick C., Slattery, Tracy, \& Sardessai, Ron. 2005.

“Determinants of innovative work behaviour: Development and test of an integrated model.” Creativity and Innovation Management 14(2): 142-150.

- Reagans, Ray, and Bill McEvily. 2003. “Network Structure and Knowledge Transfer: The Effects of Cohesion and Range.” Administrative Science Quarterly 48: 240-67

- Robertson, Peter J., Darryl R. Roberts, and Jerry I. Porras. 1993. “An Evaluation of a Model of Planned Organizational Change”, In Research in Organizational Change and Development (Vol. 7), edited by Richard W. Woodman, and William A. Pasmore, 1 -39. Greenwich, CT: JAI Press.

- Rodan, Simon. 2010. "Structural Holes and Managerial Performance: Identifying the Underlying Mechanisms.” Social Networks 32:168-79.

- Rogers, Everett M., and D. Lawrence Kincaid. 1981. Communication Networks. New York: Free Press.

- Shah, Priti Pradhan. 2000. "Network Destruction: The Structural Implications of Downsizing.” Academy of Management Journal 43: 101-12.

- Shin, Shung J., Kim, Tae Y., Lee, Jeong Y., \& Bian, Lin. 2012. “Cognitive team diversity and individual team member creativity: A cross-level interaction.” Academy of Management Journal 55(1): 197-212.

- Siggelkow, Nicolaj. 2007. “Persuasion with Case Studies.” Academy of Management Journal 50: $20-24$.

- Smith, Ken G., Christopher Collins and Kevin D. Clark. 2005. "Existing knowledge, knowledge creation capability, and the rate of new product introduction in high-technology firms.” Academy of management journal 48(2): 346-357. 
- Song, Lisa Z., Michael Song, and C. Anthony Di Benedetto. 2011. "Resources, Supplier Investment, Product Launch Advantages, and First Product Performance.” Journal of Operations Management 29: 86-104.

- Szulanski, Gabriel. 1996. "Exploring Internal Stickiness: Impediments to the Transfer of Best Practice within the Firm.” Strategic Management Journal 17: 27-43.

- Tagliaventi, Maria R., \& Mattarelli, Elisa. 2006. “The role of networks of practice, value sharing, and operational proximity in knowledge flows between professional groups.” Human Relations 59(3): 291-319.

- Tortoriello, Marco, and David Krackhardt. 2010. “Activating Cross Boundary Knowledge: The Role of Simmilian Ties in the Generation of Innovation.” Academy of Management Journal 53: 167-81.

- Tsai, Wenpin. 2000. "Social Capital, Strategic Relatedness, and the Formation of IntraOrganizational Linkages.” Strategic Management Journal 21: 925-39.

- Tsai, Wenpin. 2001. “Knowledge Transfer in Intraorganizational Networks.” Academy of Management Journal 44: 996-1004.

- $\quad$ Tyre, Marcie J., and Wanda J. Orlikowski. 1994. “Windows of Opportunity: Temporal Patterns of Technological Adaptation in Organizations.” Organization Science 5: 98-118.

- Uzzi, Brian, \& Spiro, J. 2005. “Collaboration and creativity: The small world problem.” American journal of sociology, 111(2): 447-504.

- Van der Eijk, Rene, Wilfred Dolfsma and Albert Jolink. 2009. “On a Source of Social Capital: Gift Exchange.” Journal of Business Ethics 89: 315-29.

- Van den Ende, Jan, Frederiksen, L., \& Prencipe, A. 2015. “The front end of innovation: Organizing search for ideas.” Journal of Product Innovation Management 32(4): 482-487 
- Wasserman, Stanley, and Katherine Faust. 1994. Social Network Analysis: Methods and Applications. New York: Cambridge UP.

- Whelan, Eoin, Parise, Salvatore, De Valk, Jasper, \& Aalbers, Rick. 2011. “Creating employee networks that deliver open innovation.” MIT Sloan Management Review, 53(1), 37.

- Zellmer-Bruhn, Mary E. 2003. “Interruptive Events and Team Knowledge Acquisition.” Management Science 49: 514-28.

- Zheng, Wei. 2010. A social capital perspective of innovation from individuals to nations: where is empirical literature directing us? International Journal of Management Reviews 12, $151-183$. 
Figure 1: The conceptual model

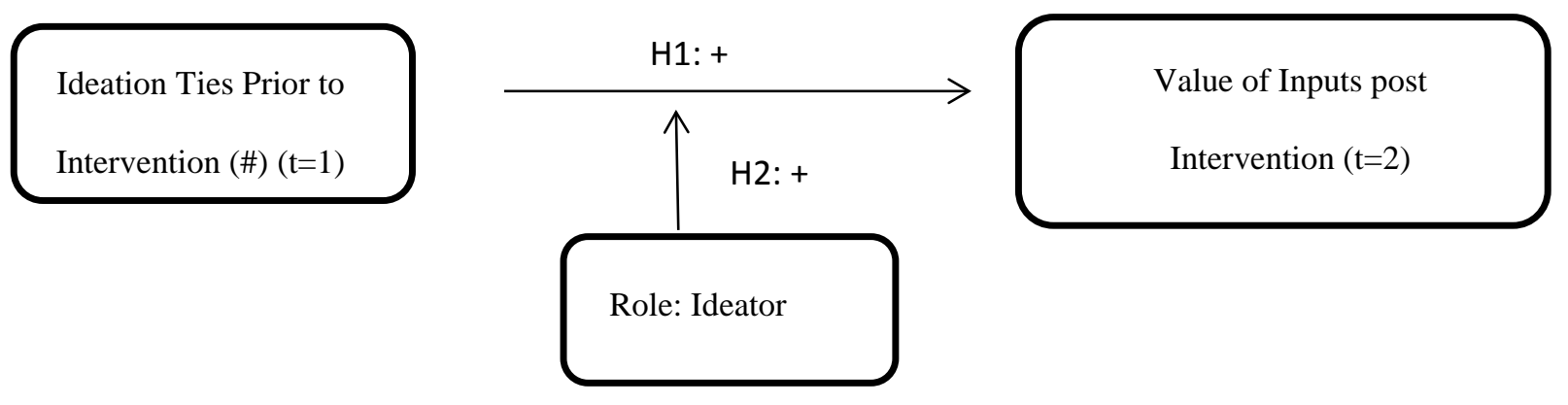

Table 1: Ideation Community over Time

\begin{tabular}{|l|l|l|l|}
\hline Number of actors in the discretionary social network & $\mathbf{t = 1}$ & Actor attrition & $\mathbf{t = 2}$ \\
\hline $\begin{array}{l}\text { Ideators } \\
\mathrm{t}=2 \text {, with ideation as a core functional capability) }\end{array}$ & 27 & 2 left the company & 25 \\
\hline $\begin{array}{l}\text { Realizers } \\
\text { with ideation as a secondary functional capability) }\end{array}$ & & & \\
\hline $\begin{array}{l}\text { Newcomers } \\
\text { only), with ideation as a secondary functional capability) }\end{array}$ & n.a. & & $102^{*}$ \\
\hline Total & $\mathbf{1 4 4}$ & & \\
\hline
\end{tabular}

* All newcomers hold the role of a 'realizer', being only secondarily involved with ideation - no additional formal ideation roles were created by the organization from $t=1$ to $t=2$.

Figure 2: The Discretionary social network, before and after intervention 

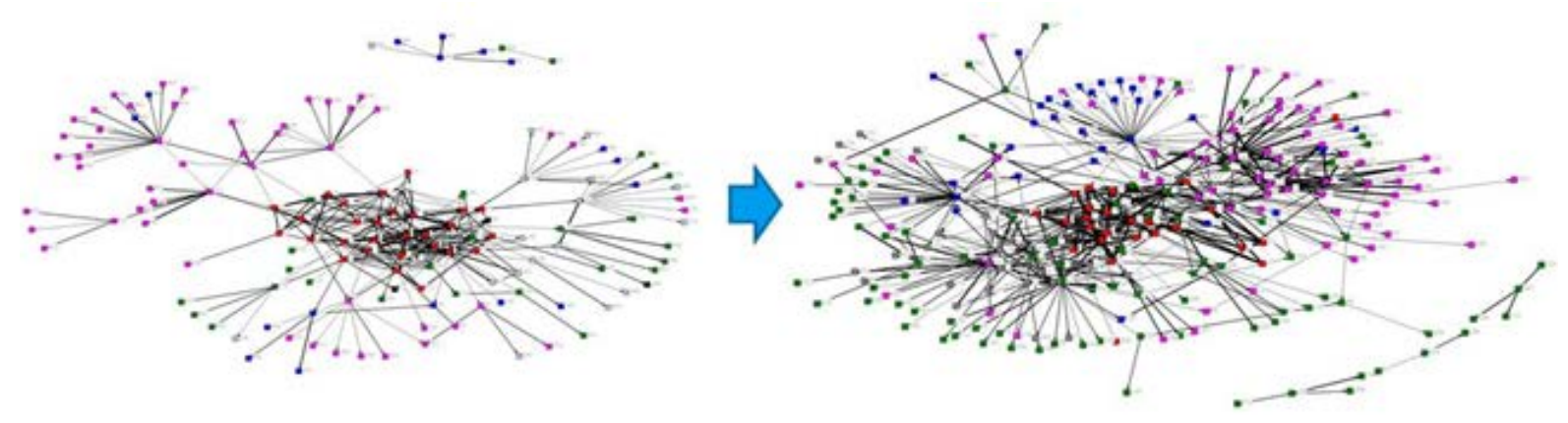

Table 1: Network survey questions

\begin{tabular}{|c|c|c|c|}
\hline Network & Name generator questions & Type & Sources \\
\hline $\begin{array}{l}\text { Formal } \\
\text { network } \\
\text { (workflow) }\end{array}$ & $\begin{array}{l}\text { Contacts prescribed by the organization } \\
\text { to carry out daily job: } \\
\text { Q: "Who are the key people that you } \\
\text { connect with to successfully carry out } \\
\text { your daily activities within the } \\
\text { organization, the contacts that are } \\
\text { prescribed or mandated by the } \\
\text { organization.” }\end{array}$ & $\begin{array}{l}\text { valued/ } \\
\text { directed }\end{array}$ & $\begin{array}{l}\text { (Mehra et al. 2001; } \\
\text { see also Brass } \\
\text { 1984; Brass and } \\
\text { Burkhardt 1992; } \\
\text { Cross and } \\
\text { Cummings 2004; } \\
\text { Whitbread et al. } \\
\text { 2011; Aalbers et al. } \\
\text { 2013) }\end{array}$ \\
\hline $\begin{array}{l}\text { Discretionary } \\
\text { social } \\
\text { network } \\
\text { (ideation } \\
\text { related) }\end{array}$ & $\begin{array}{l}\text { Contacts are useful in helping you to be } \\
\text { creative and innovative in your job, such } \\
\text { as helping you to generate new ideas: } \\
\text { Q: "With whom they voluntarily } \\
\text { exchanged new ideas, ideations and } \\
\text { substantial improvements to products } \\
\text { and services that are not part of their } \\
\text { day-to-day activities?” }\end{array}$ & $\begin{array}{l}\text { valued/ } \\
\text { directed }\end{array}$ & $\begin{array}{l}\text { (Rodan 2010; } \\
\text { Cross and Prusak } \\
\text { 2002; Aalbers et al. } \\
\text { 2013) }\end{array}$ \\
\hline
\end{tabular}


Table A1: Means, Standard Deviations, and Correlations; $t=1$ and $t=2(N=139)$

\begin{tabular}{|c|c|c|c|c|c|c|c|c|c|c|}
\hline \# & Variable (actor level) & Mean & SD & 1 & 2 & 3 & 4 & 5 & 6 & 7 \\
\hline 1 & Value-of-input ( $\mathrm{t}=2$ ) & 2.41 & 2.13 & & & & & & & \\
\hline 2 & Gender & .79 & .41 & $-.18 *$ & & & & & & \\
\hline 3 & Tenure & 8.70 & 6.32 & $-.20 *$ & .07 & .07 & & & & \\
\hline 4 & Ideator (y/n) & .19 & .39 & $.57 * * *$ & .00 & $-.27^{* *}$ & & & & \\
\hline 5 & Value-of-input ( $\mathrm{t}=1$ ) & 4.73 & 1.23 & -.10 & $.23^{*}$ & .02 & -.04 & & & \\
\hline 6 & Hierarchical level & 4.4 & .87 & .09 & -.07 & -.10 & .17 & $-.22 *$ & & \\
\hline 7 & \# Ideation Ties $(\mathrm{t}=1)$ & 2.78 & 4.53 & $.57 * * *$ & -.13 & $-.25 * *$ & $.69 * * *$ & $-.23 *$ & .17 & \\
\hline 8 & Change in \# Ideation Ties $\left(\Delta \mathrm{t}_{1}\right.$ to $\left.\mathrm{t}_{2}\right)$ & .08 & 3.82 & .18 & .16 & .11 & -.15 & $.29 * *$ & -.15 & $-.36 * * *$ \\
\hline
\end{tabular}

$* * * / * * / *$ significant at $0.1 \% / 1 \% / 5 \%$ levels respectively, $n=139$ 
Table 2: Improving Ideation Input by Management Intervention (DV = Value of input, post intervention [t=2])

Model 1 Model 2 Model 3 Model $4 \quad$ Hypotheses

\begin{tabular}{|c|c|c|c|c|c|}
\hline (Intercept) & $\begin{array}{c}1.54 \\
(1.16)\end{array}$ & $\begin{array}{c}0.68 \\
(1.16)\end{array}$ & $\begin{array}{c}1.15 \\
(0.99)\end{array}$ & $\begin{array}{c}1.09 \\
(0.94)\end{array}$ & \\
\hline Gender & $\begin{array}{l}-0.96^{*} \\
(0.44)\end{array}$ & $\begin{array}{l}-0.82 \\
(0.42)\end{array}$ & $\begin{array}{c}-0.99^{* *} \\
(0.36)\end{array}$ & $\begin{array}{l}-0.58 \\
(0.35)\end{array}$ & \\
\hline Value-of-input & $\begin{array}{l}-0.04 \\
(0.15)\end{array}$ & $\begin{array}{c}0.06 \\
(0.15)\end{array}$ & $\begin{array}{l}-0.09 \\
(0.13)\end{array}$ & $\begin{array}{l}-0.04 \\
(0.12)\end{array}$ & \\
\hline Tenure & $\begin{array}{l}-0.01 \\
(0.03)\end{array}$ & $\begin{array}{l}-0.00 \\
(0.03)\end{array}$ & $\begin{array}{l}-0.01 \\
(0.02)\end{array}$ & $\begin{array}{l}-0.03 \\
(0.02)\end{array}$ & \\
\hline Hierarchical & $\begin{array}{c}0.17 \\
(0.17)\end{array}$ & $\begin{array}{c}0.17 \\
(0.17)\end{array}$ & $\begin{array}{c}0.23 \\
(0.14)\end{array}$ & $\begin{array}{c}0.10 \\
(0.14)\end{array}$ & \\
\hline Ideator (role) $^{\mathrm{a}}$ & $\begin{array}{c}3.07^{* * *} \\
(0.45)\end{array}$ & $\begin{array}{l}1.96^{* * *} \\
(0.57)\end{array}$ & $\begin{array}{l}1.59^{* *} \\
(0.49)\end{array}$ & $\begin{array}{c}3.17^{* * *} \\
(0.68)\end{array}$ & \\
\hline $\begin{array}{l}\text { Ties in } \\
\text { Discretionary }\end{array}$ & & $\begin{array}{l}0.15^{* *} \\
(0.05)\end{array}$ & $\begin{array}{l}0.23^{* * *} \\
(0.04)\end{array}$ & $\begin{array}{l}0.38^{* * *} \\
(0.06)\end{array}$ & H1: $\sqrt{ }$ \\
\hline $\begin{array}{l}\text { Hypothesis } \\
\text { specific Control: }\end{array}$ & & & & & \\
\hline $\begin{array}{l}\text { Increase in } \\
\text { Number of Ties }\end{array}$ & & & $\begin{array}{l}0.27^{* * *} \\
(0.04)\end{array}$ & $\begin{array}{l}0.37^{* * *} \\
(0.05)\end{array}$ & \\
\hline Moderation: & & & & & \\
\hline $\begin{array}{l}\text { Ties in } \\
\text { Discretionary }\end{array}$ & & & & $\begin{array}{c}-0.31^{* * *} \\
(0.09)\end{array}$ & H2: $x$ \\
\hline $\begin{array}{l}\text { Hypothesis } \\
\text { specific Control: }\end{array}$ & & & & & \\
\hline $\begin{array}{l}\text { Increase in } \\
\text { Number of Ties } \\
\text { in Discretionary }\end{array}$ & & & & $\begin{array}{l}-0.28^{* *} \\
(0.08)\end{array}$ & \\
\hline$\overline{\mathrm{R}^{2}}$ & 0.37 & 0.42 & 0.59 & 0.64 & \\
\hline Adj. $R^{2}$ & 0.34 & 0.39 & 0.56 & 0.61 & \\
\hline $\mathrm{N}$ & 115 & 115 & 115 & 115 & \\
\hline RMSE & 1.85 & 1.78 & 1.51 & 1.41 & \\
\hline
\end{tabular}

